\title{
Cochrane
}

Library

Cochrane Database of Systematic Reviews

\section{Rescue high frequency oscillatory ventilation versus conventional ventilation for pulmonary dysfunction in preterm infants (Review)}

Bhuta T, Henderson-Smart DJ

Bhuta T, Henderson-Smart DJ.

Rescue high frequency oscillatory ventilation versus conventional ventilation for pulmonary dysfunction in preterm infants.

Cochrane Database of Systematic Reviews 1998, Issue 2. Art. No.: CD000438.

DOI: 10.1002/14651858.CD000438.

www.cochranelibrary.com

Rescue high frequency oscillatory ventilation versus conventional ventilation for pulmonary dysfunction in preterm infants (Review)

Copyright $\odot 2010$ The Cochrane Collaboration. Published by John Wiley \& Sons, Ltd. 
TABLE OF CONTENTS

HEADER 1

ABSTRACT

PLAIN LANGUAGE SUMMARY

BACKGROUND

OBJECTIVES

METHODS

RESULTS

DISCUSSION

AUTHORS' CONCLUSIONS

REFERENCES

CHARACTERISTICS OF STUDIES

DATA AND ANALYSES

Analysis 1.1. Comparison 1 Rescue HFOV vs CV in preterm infants, Outcome 1 Any new PAL among infants examined.

Analysis 1.2. Comparison 1 Rescue HFOV vs CV in preterm infants, Outcome 2 New PIE among infants examined.

Analysis 1.3. Comparison 1 Rescue HFOV vs CV in preterm infants, Outcome 3 New gross PAL among infants examined.

Analysis 1.4. Comparison 1 Rescue HFOV vs CV in preterm infants, Outcome 4 Death by 30 days.

Analysis 1.5. Comparison 1 Rescue HFOV vs CV in preterm infants, Outcome 5 IPPV at 30 days.

Analysis 1.6. Comparison 1 Rescue HFOV vs CV in preterm infants, Outcome 6 Death or IPPV at 30 days.

Analysis 1.7. Comparison 1 Rescue HFOV vs CV in preterm infants, Outcome 7 Any IVH among infants examined.

Analysis 1.8. Comparison 1 Rescue HFOV vs CV in preterm infants, Outcome 8 Grade 3 or 4 IVH among infants examined. WHAT'S NEW

HISTORY

CONTRIBUTIONS OF AUTHORS

DECLARATIONS OF INTEREST

SOURCES OF SUPPORT

INDEX TERMS

(1) 
[Intervention Review]

\section{Rescue high frequency oscillatory ventilation versus conventional ventilation for pulmonary dysfunction in preterm infants}

Tushar Bhuta1 ${ }^{\text {, David J Henderson-Smart² }}$

1Department of Neonatal Medicine, Royal North Shore Hospital, Sydney, Australia. 2NSW Centre for Perinatal Health Services Research, Queen Elizabeth II Research Institute, Sydney, Australia

Contact address: David J Henderson-Smart, NSW Centre for Perinatal Health Services Research, Queen Elizabeth II Research Institute, Building DO2, University of Sydney, Sydney, NSW, 2006, Australia.dhs@mail.usyd.edu.au.

Editorial group: Cochrane Neonatal Group

Publication status and date: Edited (no change to conclusions), published in Issue 1, 2010.

Citation: Bhuta T, Henderson-Smart DJ. Rescue high frequency oscillatory ventilation versus conventional ventilation for pulmonary dysfunction in preterm infants. Cochrane Database of Systematic Reviews 1998, Issue 2. Art. No.: CD000438. DOI: 10.1002/14651858.CD000438.

Copyright @ 2010 The Cochrane Collaboration. Published by John Wiley \& Sons, Ltd.

\section{A B S T R A C T}

\section{Background}

Despite the increased use of antenatal steroids and surfactant replacement therapy, pulmonary disease, principally due to the respiratory distress syndrome (RDS), continues to be a major cause of mortality and morbidity in neonates. In addition to immaturity, lung distension during conventional ventilation (CV) is thought to be responsible for pulmonary air leak (PAL) and, together with oxygen toxicity, may be important in the cause of chronic lung disease (CLD). Studies of animals have suggested that high frequency oscillatory ventilation (HFOV) is an effective method of providing ventilation and oxygenation in severe experimental pulmonary disease and may result in less lung injury.

\section{Objectives}

To determine the effects of HFOV compared to conventional ventilation (CV) on pulmonary air leak and CLD in preterm infants with very severe lung disease requiring ventilation.

\section{Search methods}

A search was carried out for all randomised controlled trials from MEDLINE (1980 - April 2007) and EMBASE (1982 - April 2007$)$ using the MeSH and text terms, "high frequency ventilation", "high frequency oscillatory ventilation", "oscillatory ventilation". The Oxford Database of Perinatal Trials and trials identified by the Neonatal Review Group of the Cochrane Collaboration (CENTRAL, The Cochrane Library, Issue 2 2007) were also reviewed. Information was also sought from experts in the field, cross references from studies and proceedings of meetings of the American Society for Pediatric Research (1991 - 2006).

\section{Selection criteria}

Randomised controlled trials of HFOV vs. CV as rescue therapy in preterm infants with severe pulmonary dysfunction.

\section{Data collection and analysis}

The standard review method of the Neonatal Review Group was used. This includes independent quality assessment and data extraction by the second author. Relative risk (RR), risk difference (RD) and number needed to treat (NNT) were used to express treatment effects.

\section{Main results}

Only one trial was found and this showed that rescue HFOV caused a reduction in any new pulmonary air leak (PAL) [RR 0.73 (95\% $\mathrm{Cl}$ $0.55,0.96)$, RD $-0.17(95 \% \mathrm{Cl}-0.32,-0.03)]$. The number of infants that needed to be treated (NNT) to prevent one infant having any PAL was 
six $(95 \% \mathrm{Cl} 3,37)$. There was no significant difference in the rate of PIE or of gross pulmonary air leak, such as pneumomediastinum or pneumothorax. There was no significant effect on mortality or the use of IPPV at 30 days.

The rate of intraventricular haemorrhage (IVH) of any grade was increased in infants treated with HFOV, [RR 1.77 (95\% Cl 1.06, 2.96), RD $0.16(95 \% \mathrm{Cl} 0.02,0.29)]$. Thus, for every six infants $(95 \% \mathrm{Cl} 3,50)$ given rescue HFOV, one infant developed IVH of any grade. There was a stronger, but non-significant trend towards an increase in severe IVH (grades 3 or 4 IVH).

\section{Authors' conclusions}

There is insufficient information on the use of rescue HFOV to make recommendations for practice. The small amount of data that exists suggest that harm might outweigh any benefit. Any future use of HFOV as rescue therapy for preterm infants with severe RDS should be within randomised controlled trials and address important outcomes such as longer term pulmonary and neurological function.

\section{PLAIN LANGUAGE SUMMARY}

\section{Rescue high frequency oscillatory ventilation versus conventional ventilation for pulmonary dysfunction in preterm infants}

Insufficient evidence exists to support the use of high frequency oscillatory ventilation instead of conventional ventilation for preterm infants with severe lung disease who are given positive pressure ventilation. High frequency oscillatory ventilation (HFOV) is a newer way of providing artificial ventilation of the lungs. Theoretically, HFOV may produce less injury to the lungs, particularly when high pressures are used on conventional positive pressure ventilation. This review of the evidence from one randomised controlled trial suggests there might be less short-term lung injury from high frequency oscillatory ventilation. However, more babies in this group developed haemorrhage in and around the fluid spaces in the brain (cerebral ventricles) and this harm might outweigh any benefit. More information is needed to clarify the balance between benefits and harms of high frequency oscillatory ventilation instead of conventional positive pressure ventilation for preterm infants with severe lung disease. 


\section{B A C K G R O U N D}

Despite the increased use of antenatal steroids and surfactant replacement therapy, pulmonary disease, principally due to the respiratory distress syndrome (RDS), continues to be a major cause of mortality and morbidity in neonates. In addition to immaturity, lung distension during conventional ventilation (CV) is thought to be responsible for pulmonary air leak (PAL) and, together with oxygen toxicity, may be important in the cause of chronic lung disease (CLD) (Jobe 2002).

Studies of animals have suggested that HFOV is an effective method of providing ventilation and oxygenation in severe experimental pulmonary disease (Truog 1984; deLemos 1987; Gerstmann 1988) and may also reduce the severity of lung injury. An uncontrolled rescue study indicated that it may be valuable in the management of infants with pulmonary interstitial emphysema, a form of PAL (Clark 1986). Infants at risk of morbidity and mortality from PAL can be identified on the basis of low birth weight and the severity of their lung disease, as indicated by the high peak inspiratory pressures on IPPV (Gaylord 1985).

\section{OB JECTIVES}

To determine the effect of HFOV as compared to CV on PAL, CLD in preterm infants with severe lung disease requiring ventilation.

Hypotheses to be tested by subgroup analyses nominated a priori:

1) Benefits are greater and harm less if rescue HFOV is applied using strategies aimed at maintaining a high lung volume, such as use of higher mean airway pressures, manoeuvres that increase alveolar recruitment after suctioning, and weaning of $\mathrm{FiO} 2$ before pressure.

2) Both benefits (in terms of PAL and CLD) and harm (IVH) are increased with rescue HFOV vs. CV at lower gestational age and birth weight, due to higher baseline risks.

3) Benefits of rescue HFOV vs. CV are greater in trials that used surfactant replacement therapy, which improves alveolar stability and increases compliance.

\section{METHODS}

\section{Criteria for considering studies for this review}

\section{Types of studies}

All randomised quasi-randomised controlled trials were eligible.

\section{Types of participants}

Preterm infants with severe pulmonary dysfunction, principally due to RDS. Severe lung disease was defined as severe RDS on chest $X$-ray with or without interstitial air, in an infant on IPPV with high inspired oxygen, high peak and mean airway pressures.

\section{Types of interventions}

HFOV as rescue therapy vs. CV. Trials were classified as rescue when patients were randomised after failure to adequately ventilate on $\mathrm{CV}$, or when complications of CV such as PAL developed or were likely to develop.

\section{Types of outcome measures}

1) Mortality at 28 - 30 days and at discharge

2) Pulmonary air leak (PAL) that developed during treatment i) new, moderate or severe pulmonary interstitial emphysema (PIE) ii) any new pulmonary air leak

iii) new, gross pulmonary air leak (pneumomediastinum or pneumothorax)

3) Chronic lung disease

i) CLD (oxygen therapy with or without an abnormal chest X-ray, or use of mechanical ventilation at 28 days of age)

ii) Severe CLD (oxygen therapy at 36 or more weeks postmenstrual age)
4) Intraventricular haemorrhage
i) all grades
ii) grades 3 or 4
5) Periventricular leukomalacia
6) Pulmonary and neurodevelopmental outcomes in childhood

\section{Search methods for identification of studies}

A search was carried out for all randomised controlled trials from MEDLINE (1980 - April 2007) and EMBASE (1982 - April 2007) using the MeSH and text terms, "high frequency ventilation", "high frequency oscillatory ventilation", "oscillatory ventilation". The Oxford Database of Perinatal Trials and trials identified by the Cochrane Neonatal Review Group (CENTRAL, The Cochrane Library, Issue 2, 2007) were also reviewed. Information was also sought from experts in the field, cross references from studies and proceedings of meetings of the American Society for Pediatric Research (1991 - 2006).

\section{Data collection and analysis}

The standard review method of the Neonatal Review Group was used. This included independent quality assessment by the second author. Each author extracted data separately, then compared results and resolved differences.

The standard method of the Neonatal Review Group was used to analyse data, with calculation of relative risk (RR) and risk difference (RD). From 1/RD the number needed to treat (NNT) for beneficial effects, and number needed to harm (NNH) for adverse effects, were calculated.

\section{RE S U L T S}

\section{Description of studies}

Only one trial was found (HIFO 1993). One hundred and eighty two preterm infants (less than 35 weeks gestational age and birth weight more than 500 grams) with severe RDS (high peak and mean ventilator pressures, high inspired oxygen and low $\mathrm{PaO}_{2} /$ $\mathrm{PAO}_{2}$ ratios) who had, or were at risk of, developing PAL were entered.

Infants could be randomised up to 48 hours of age and the mean age for HFOV was 21 hours and for CV 22 hours. The primary outcome was development or worsening of PAL. PIE was graded as mild (perihilar or focal bubbles of any size); moderate (diffuse bubbles < 
$2 \mathrm{~mm}$ ); and severe (diffuse bubbles $>2 \mathrm{~mm}$ ). Gross PAL was defined as pneumomediastinum or pneumothorax. The data used in the meta-analysis were 'moderate or severe PIE' or the 'presence of gross PAL' in infants who developed PAL during the treatment phase of the trial and those whose PAL progressed during this period (HIFO 1993 table III).

A number of other studies were found that evaluated the elective use of HFOV (infants were eligible if they had RDS and as soon as they were given IPPV), typically being randomised in the first 12 hours of life. They are the subject of another review in The Cochrane Library (Henderson-Smart 2003).

\section{Risk of bias in included studies}

The subjects were randomised but concealment was unclear. The treatment was not blinded. Three infants in each group were excluded from analysis because of protocol violations. The primary outcome of PAL was blindly assessed, while the blinding of head ultrasound assessments for IVH was not specified. Complete pre and post-entry chest $x$-rays were available for 83 (97\%) HFOV infants and $87(97 \%) \mathrm{CV}$ infants. IVH was assessed by cranial ultrasound in 81 (94\%) HFOV infants and 84 (93\%) CV infants.

\section{Effects of interventions}

\section{RESCUE HIGH FREQUENCY OSCILLATORY VENTILATION VS CONVENTIONAL VENTILATION FOR PULMONARY DYSFUNCTION IN PRETERM INFANTS}

\section{Pulmonary outcomes (Outcomes 01.01 - 01.05):}

Rescue HFOV resulted in a reduction in any new pulmonary air leak (PAL) [RR $0.73(95 \% \mathrm{Cl} 0.55,0.96), \mathrm{RD}-0.17(95 \% \mathrm{Cl}-0.32,-0.03)]$. The number of infants that needed to be treated (NNT) to prevent one infant having any PAL was six $(95 \% \mathrm{Cl} 3,37)$. There was no significant difference in the rate of PIE [RR $1.22(95 \% \mathrm{Cl} 0.78,1.89)]$ or of gross pulmonary air leak such as pneumomediastinum or pneumothorax [RR $0.80(95 \% \mathrm{Cl} 0.45,1.42)]$. Use of IPPV at 30 days was not significantly different in the HFOV and CV groups [RR 0.94 (95\% Cl 0.54, 1.66).

\section{Mortality (Outcome 01.04 and 01.06):}

Mortality rates at 28 - 30 days of age were not significantly different [RR $0.94(95 \% \mathrm{Cl} 0.54,1.66)])$, nor were the rates of the combined outcome 'death or IPPV' at 30 days [RR $1.02(95 \% \mathrm{Cl} 0.72,1.45)$ ]. Other measures such as death at discharge and CLD at 36 weeks PMA, are not reported.

\section{Neurological outcomes (Outcomes 01.07 and 01.08):}

The rate of intraventricular haemorrhage (IVH) of any grade was increased in infants treated with HFOV [RR $1.77(95 \% \mathrm{Cl} 1.06,2.96)$, RD $0.16(95 \% \mathrm{Cl} 0.02,0.29)]$. Thus for every six infants $(95 \% \mathrm{Cl} 3,50)$ given rescue HFOV, one infant developed IVH of any grade. There was a stronger but non-significant trend towards an increase in the more severe grades 3 or 4 IVH [ RR $3.11(0.65,14.97)]$. Rates of periventricular leukomalacia were not reported.

The intended subgroup analyses could not be performed because all infants in the trial were given HFOV using a 'high volume strategy'; surfactant was administered to a minority of infants and their data were not reported separately; and, although infants were stratified by birth weight at randomisation, data were not reported by these strata.

\section{DISCUSSION}

The single trial examined in this review had the primary aim of reducing pulmonary air leak in infants at great risk due to severe RDS and reducing the use of mechanical ventilation. It was carried out before the general availability of surfactant, when severe pulmonary air leak was a greater problem. The relevance of any reported benefits in current clinical practice is uncertain. Longer term pulmonary outcomes, such as use of oxygen therapy at 36 weeks postmenstrual age or at home, were not reported.

Of concern is the increased rate of IVH and the lack of information on PVL and on neurodevelopmental follow up.

The results were similar to those observed in the reviews of elective use of HFOV (Henderson-Smart 2003) and the elective use of high frequency jet ventilation (Bhuta 1998a). In these latter reviews, both benefits, in terms of pulmonary outcomes, and harms, in terms of ultrasound evidence of brain injury, were found. There was a suggestion from subgroup analyses in these reviews that brain injury might be associated with the use of lower mean airway pressures during HFOV and high frequency jet ventilation. The only trial in the present review used a high volume strategy, so this evaluation could not be made in this review.

Another Cochrane Review examined the use of rescue HFOV in term or near term infants (Bhuta 2006).

\section{AUTHORS' CONCLUSIONS}

\section{Implications for practice}

There is insufficient information on the use of rescue HFOV to make recommendations for practice. The small amount of data that exists suggest that harm might outweigh any benefit. For every six infants who are treated with rescue HFOV rather than CV, one case of pulmonary air leak of any type would be prevented and one case of IVH of any grade would be caused.

\section{Implications for research}

Any future use of HFOV as rescue therapy for preterm infants with severe RDS should be within randomised controlled trials and address important outcomes such as longer term pulmonary and neurological function. 


\section{REFERE N C E S}

\section{References to studies included in this review \\ HIFO 1993 \{published data only\}}

HIFO Study Group. Randomized study of high-frequency oscillatory ventilation in infants with severe respiratory distress syndrome. Journal of Pediatrics 1993;122:609-19.

\section{Additional references}

\section{Bhuta 1998a}

Bhuta T, Henderson-Smart DJ. Elective high frequency jet ventilation vs conventional ventilation in preterm infants mechanically ventilated for respiratory distress syndrome. Cochrane Database of Systematic Reviews 1998, Issue 2.

\section{Bhuta 2006}

Bhuta T, Clark RH, Henderson-Smart DJ. Rescue high frequency oscillatory ventilation vs conventional ventilation for infants with severe pulmonary dysfunction born at or near term. Cochrane Database of Systematic Reviews 2006, Issue 1.

\section{Clark 1986}

Clark RH, Gerstmann DR, Null DM, Yoder BA, Cornish JD, Glasier CM, et al. Pulmonary interstial emphysema treated by high-frequency oscillatory ventilation. Critical Care Medicine 1986;14:926-30.

\section{deLemos 1987}

deLemos RA, Coalson JJ, Gerstmann DR, Null DM Jr, Ackerman NB, Escobedo MB, et al. Ventilatory management of infant baboons with hyaline membrane disease; the use of high frequency ventilation. Pediatric Research 1987;21:594-602.

\section{Gaylord 1985}

Gaylord MS, Theime RE, Woodall DL, Quissell BJ. Predicting mortality in low-birth-weight infants with pulmonary interstitial emphysema. Pediatrics 1985;76:219-24.

\section{Gerstmann 1988}

Gerstmann DR, deLemos RA, Coalson JJ, Clark RH, Wiswell TE, Winter DC, et al. Influence of ventilatory technique on

\section{CHARACTERISTICS OF STUDIES}

Characteristics of included studies [ordered by study ID] pulmonary baroinjury in baboons with hyaline membrane disease. Pediatric Pulmonology 1988;5:82-91.

\section{Henderson-Smart 2003}

Henderson-Smart DJ, Bhuta T, Cools F, Offringa M. Elective high frequency oscillatory ventilation versus conventional ventilation for acute pulmonary dysfunction in preterm infants. Cochrane Database of Systematic Reviews 2003, Issue 4.

\section{Jobe 2002}

Jobe AH, Ikegami M. Lung development and function in preterm infants in the surfactant treatment era. Annual Review Physiology 2000;62:825-46.

\section{Truog 1984}

Truog WE, Standaert TA, Murphy JH, Woodrum DE, Hodson WA. Effects of prolonged high frequency oscillatory ventilation in premature primates with experimental hyaline membrane disease. American Review of Respiratory Disease 1984;130:76-80.

\section{References to other published versions of this review Bhuta 1998}

Bhuta T, Henderson-Smart DJ. Rescue high frequency oscillatory ventilation versus conventional ventilation for pulmonary dysfunction in preterm infants. Cochrane Database of Systematic Reviews 1998, Issue 1.

\section{Bhuta 2003}

Bhuta T, Henderson-Smart DJ. Rescue high frequency oscillatory ventilation versus conventional ventilation for pulmonary dysfunction in preterm infants. Cochrane Database of Systematic Reviews 2003, Issue 1.

\section{Bhuta 2004}

Bhuta T, Henderson-Smart DJ. Rescue high frequency oscillatory ventilation versus conventional ventilation for pulmonary dysfunction in preterm infants. Cochrane Database of Systematic Reviews 2004, Issue 4.

HIFO 1993

Methods Concealment at randomization - can't tell; blinding of treatment - no; completeness of followup - yes [6 (3\%) excluded after randomization] and blind assessment of primary outcome (PAL) - yes. It was unclear if cranial ultrasounds were read blind.

Participants Preterm infants ( $\mathrm{n}=182,<35$ weeks and $>500 \mathrm{~g}$ birth weight, aged up to $48 \mathrm{hrs}$ ) with severe RDS and at risk of developing PAL. Age in hours at entry $21 \mathrm{~h}$ (SD 13) in HFOV group and 22h (SD 13) in CV group.

Interventions Rescue HFOV ( $n=89$ ) using Sensormedics $3100,15 \mathrm{~Hz}$, MAP 2-3 cms H20 greater than on CV, no augmented breaths. 
HIFO 1993 (Continued)

$\mathrm{CV}(\mathrm{n}=92)$ pressure limited, time cycled Sechrist ventilator, IT 0.3-0.5, rate $40-80 / \mathrm{min}$, PEEP $4-6 \mathrm{cms}$ $\mathrm{H} 2 \mathrm{O}$.

\begin{tabular}{ll}
\hline Outcomes & $\begin{array}{l}\text { Any PAL, new air leak, pneumothorax or pneumomediastinum, death by } 30 \text { days, IPPV at } 30 \text { days, death } \\
\text { or IPPV at } 30 \text { days, all IVH and grades } 3 \text { or } 4 \text { IVH. }\end{array}$
\end{tabular}
or IPPV at 30 days, all IVH and grades 3 or 4 IVH.

Notes Majority of infants not treated with surfactant ( $83 \%$ of HFOV and $79 \%$ of CV).

\section{Risk of bias}

\begin{tabular}{lll}
\hline Bias & Authors' judgement & Support for judgement \\
\hline Allocation concealment? & Unclear risk & B - Unclear \\
\hline
\end{tabular}

\section{DATA AND ANALYSES}

\section{Comparison 1. Rescue HFOV vs CV in preterm infants}

\begin{tabular}{|c|c|c|c|c|}
\hline Outcome or subgroup title & $\begin{array}{l}\text { No. of } \\
\text { studies }\end{array}$ & $\begin{array}{l}\text { No. of } \\
\text { partici- } \\
\text { pants }\end{array}$ & Statistical method & Effect size \\
\hline $\begin{array}{l}1 \text { Any new PAL among infants exam- } \\
\text { ined }\end{array}$ & 1 & 170 & Risk Ratio (M-H, Fixed, 95\% Cl) & $0.73[0.55,0.96]$ \\
\hline 2 New PIE among infants examined & 1 & 170 & Risk Ratio (M-H, Fixed, 95\% Cl) & $1.22[0.78,1.89]$ \\
\hline $\begin{array}{l}3 \text { New gross PAL among infants exam- } \\
\text { ined }\end{array}$ & 1 & 170 & Risk Ratio (M-H, Fixed, 95\% Cl) & $0.80[0.45,1.42]$ \\
\hline 4 Death by 30 days & 1 & 176 & Risk Ratio (M-H, Fixed, 95\% Cl) & $1.11[0.61,2.01]$ \\
\hline 5 IPPV at 30 days & 1 & 176 & Risk Ratio (M-H, Fixed, 95\% Cl) & $0.94[0.54,1.66]$ \\
\hline 6 Death or IPPV at 30 days & 1 & 176 & Risk Ratio (M-H, Fixed, 95\% Cl) & $1.02[0.72,1.45]$ \\
\hline 7 Any IVH among infants examined & 1 & 165 & Risk Ratio (M-H, Fixed, 95\% Cl) & $1.77[1.06,2.96]$ \\
\hline $\begin{array}{l}8 \text { Grade } 3 \text { or } 4 \text { IVH among infants ex- } \\
\text { amined }\end{array}$ & 1 & 165 & Risk Ratio (M-H, Fixed, 95\% Cl) & $3.11[0.65,14.97]$ \\
\hline
\end{tabular}

Analysis 1.1. Comparison 1 Rescue HFOV vs CV in preterm infants, Outcome 1 Any new PAL among infants examined.

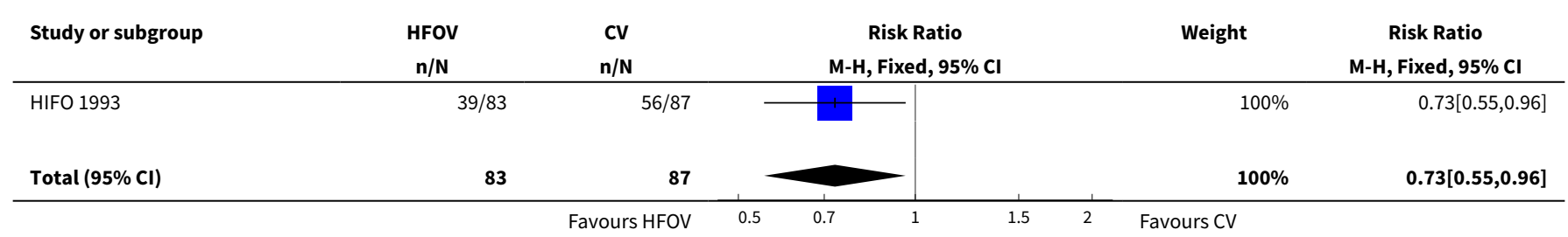




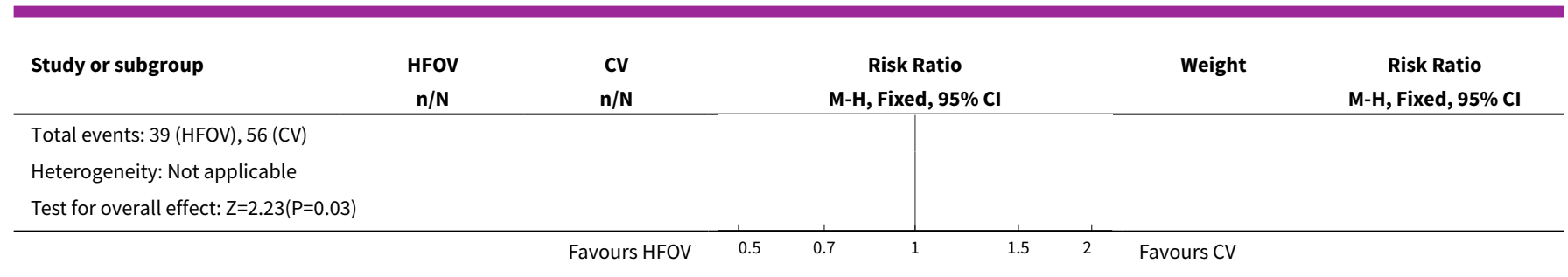

\section{Analysis 1.2. Comparison 1 Rescue HFOV vs $\mathrm{CV}$ in preterm infants, Outcome 2 New PIE among infants examined.}

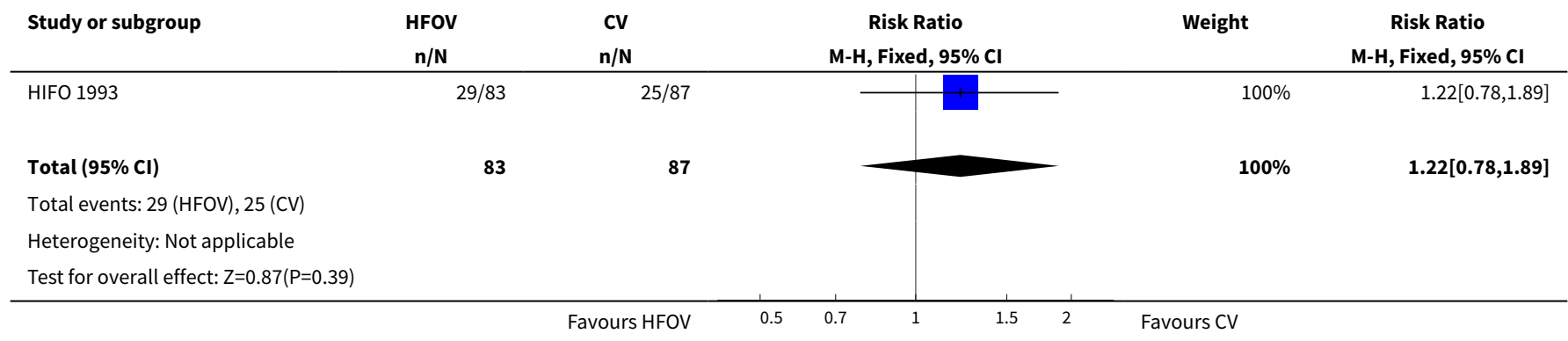

Analysis 1.3. Comparison 1 Rescue HFOV vs CV in preterm infants, Outcome 3 New gross PAL among infants examined.

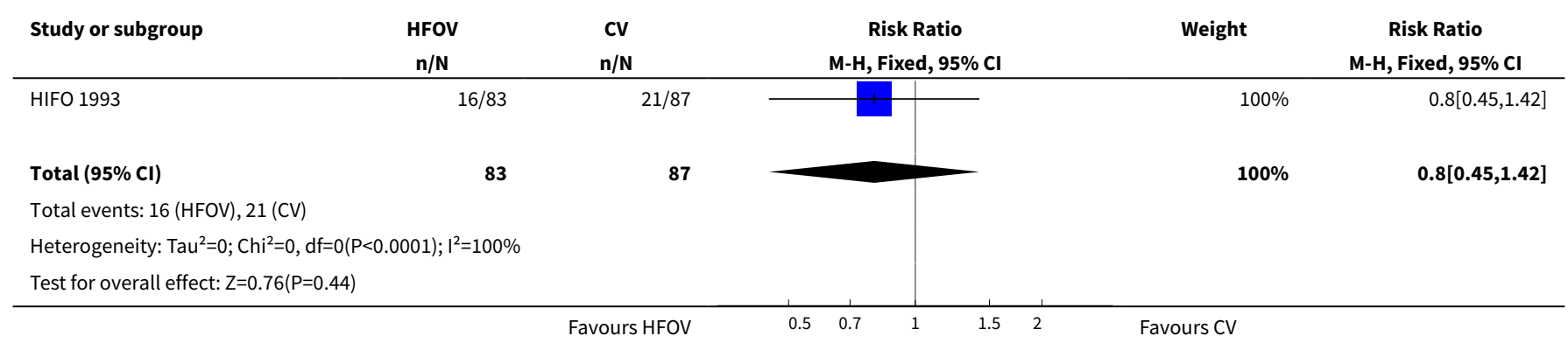

Analysis 1.4. Comparison 1 Rescue HFOV vs CV in preterm infants, Outcome 4 Death by 30 days.

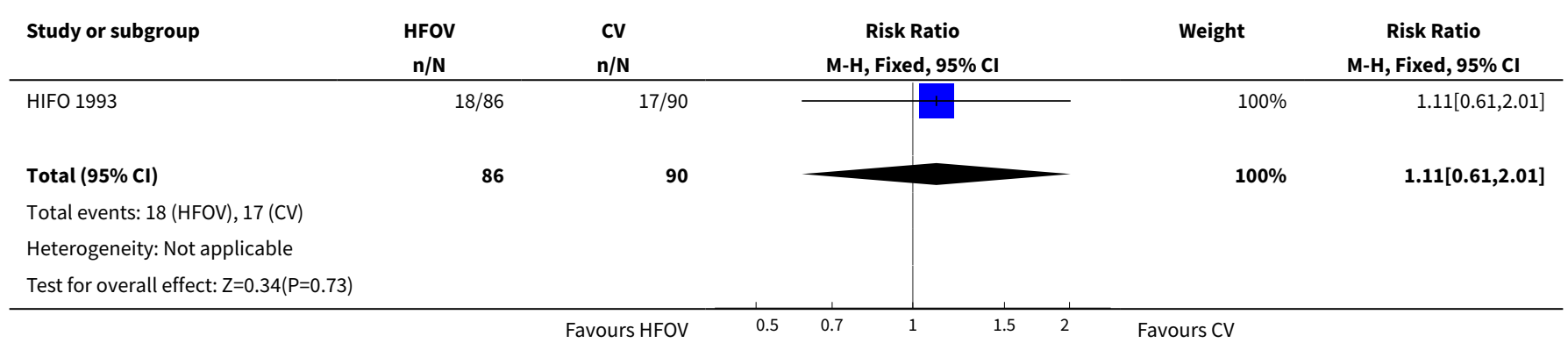


Analysis 1.5. Comparison 1 Rescue HFOV vs CV in preterm infants, Outcome 5 IPPV at 30 days.

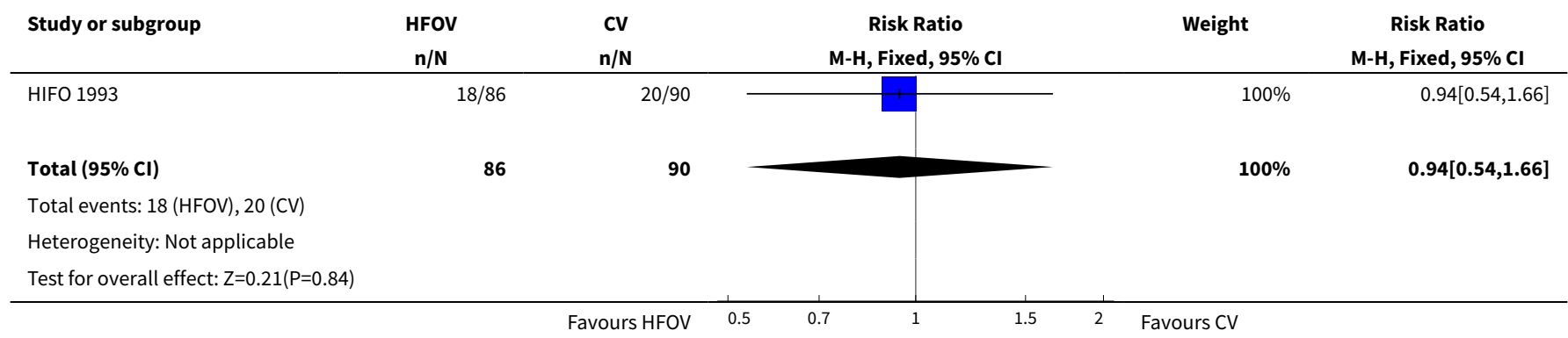

Analysis 1.6. Comparison 1 Rescue HFOV vs CV in preterm infants, Outcome 6 Death or IPPV at 30 days.

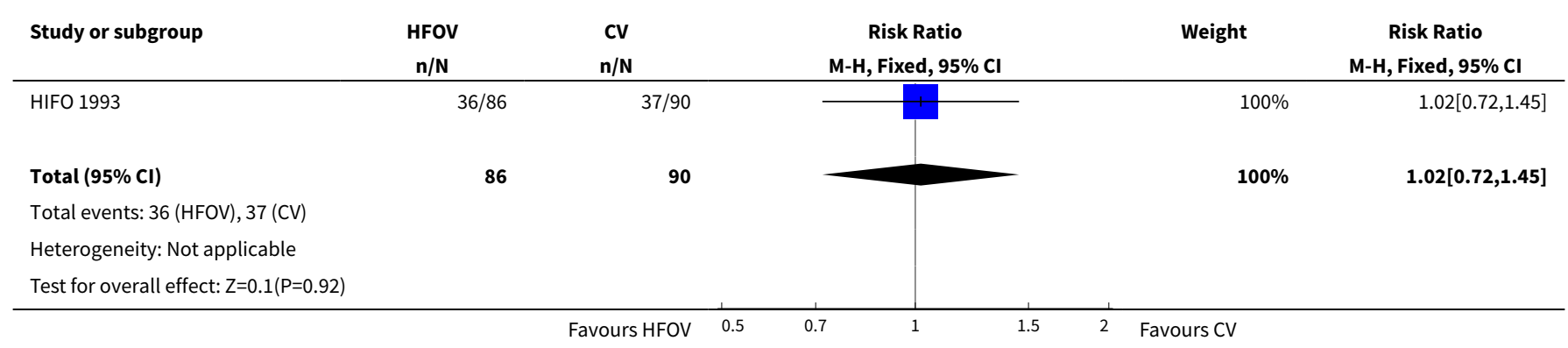

Analysis 1.7. Comparison 1 Rescue HFOV vs CV in preterm infants, Outcome 7 Any IVH among infants examined.

\begin{tabular}{|c|c|c|c|c|c|}
\hline Study or subgroup & $\begin{array}{c}\text { HFOV } \\
\mathrm{n} / \mathrm{N}\end{array}$ & $\begin{array}{c}\text { CV } \\
n / N\end{array}$ & $\begin{array}{c}\text { Risk Ratio } \\
\text { M-H, Fixed, 95\% Cl }\end{array}$ & Weight & $\begin{array}{c}\text { Risk Ratio } \\
\text { M-H, Fixed, } 95 \% \mathrm{Cl}\end{array}$ \\
\hline HIFO 1993 & $29 / 81$ & $17 / 84$ & & $100 \%$ & $1.77[1.06,2.96]$ \\
\hline Total $(95 \% \mathrm{Cl})$ & 81 & 84 & & $100 \%$ & $1.77[1.06,2.96]$ \\
\hline \multicolumn{6}{|c|}{ Total events: 29 (HFOV), 17 (CV) } \\
\hline \multicolumn{6}{|c|}{ Heterogeneity: Not applicable } \\
\hline Test for overall effec & & & & & \\
\hline
\end{tabular}

Analysis 1.8. Comparison 1 Rescue HFOV vs $\mathrm{CV}$ in preterm infants, Outcome 8 Grade 3 or 4 IVH among infants examined.

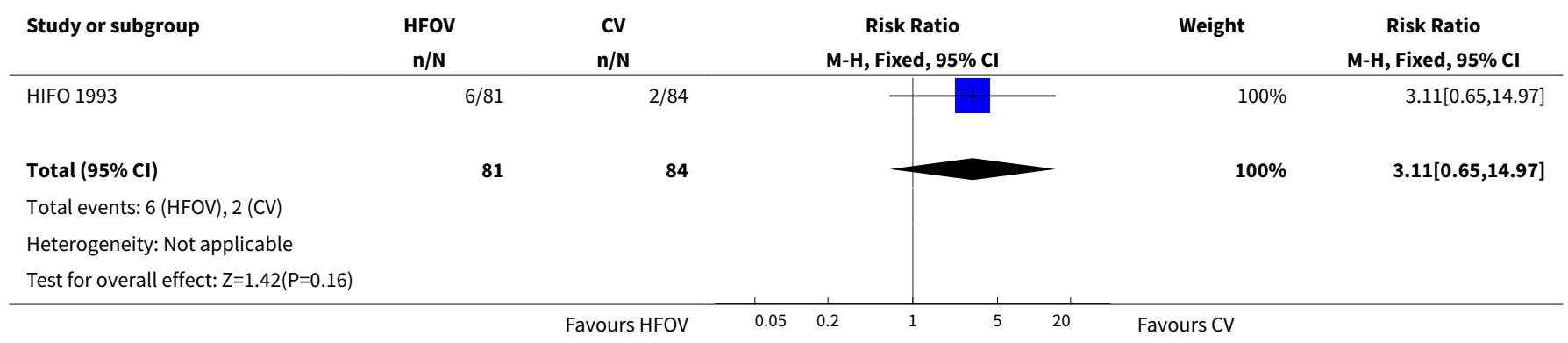


WHAT'S NEW

\begin{tabular}{lll}
\hline Date & Event & Description \\
\hline 21 May 2008 & Amended & Converted to new review format. \\
\hline
\end{tabular}

\section{HIST ORY}

Protocol first published: Issue 3, 1997

Review first published: Issue 1, 1998

\begin{tabular}{lll}
\hline Date & Event & Description \\
\hline 23 August 2007 & New search has been performed & $\begin{array}{l}\text { This updates the review 'Rescue high frequency oscillatory ven- } \\
\text { tilation versus conventional ventilation for pulmonary dysfunc- } \\
\text { tion in preterm infants' published in The Cochrane Library, Issue } \\
4,2004 \text { (Bhuta 2004). }\end{array}$ \\
& & $\begin{array}{l}\text { The searches have been updated to April 2007. No new trials } \\
\text { have been identified in these updated searches. }\end{array}$ \\
\hline 19 December 1997 & New citation required and conclusions & Substantive amendment \\
& have changed & \\
\hline
\end{tabular}

\section{CONTRIBUTIONS OF AUTHORS}

Both review authors developed the protocol, evaluated trials and extracted data.

Henderson-Smart wrote the review and entered data into RevMan.

Henderson-Smart has been responsible for searching for trials and updating the review with approval of Bhuta.

\section{DECLARATIONS OF INTEREST}

None

\section{SOURCES OF SUPPORT}

\section{Internal sources}

- NSW Centre for Perinatal Health Services Research, University of Sydney, Australia.

- Department of Neonatology, Royal North Shore Hospital, Sydney, Australia.

- Royal Prince Alfred Hospital, Sydney, Australia.

\section{External sources}

- No sources of support supplied

\section{INDEX TERMS}

\section{Medical Subject Headings (MeSH)}

*High-Frequency Ventilation; Infant, Premature; Infant, Premature, Diseases [therapy]; Lung Diseases [therapy]; Respiration, Artificial; Respiratory Distress Syndrome, Newborn [*therapy]

\section{MeSH check words}

Humans; Infant, Newborn 